\title{
Synthesis and Study of New Fluorescent Copolyamides
}

\author{
P. Subramanian and K. Venkatarao \\ Department of Physical Chemistry, University of Madras, \\ Guindy Campus, Madras 600 025, India
}

(Received July 2, 1982)

\begin{abstract}
New fluorescent aromatic copolyamides were synthesized by condensing (i) a mixture of 4,4'-[1,4-phenylenebis(methylidyne nitrilo)]-di(benzoyl chloride) (I) and terephthaloyl chloride (II) with 4,4'-diaminodiphenyl ether and 4,4'-diaminobibenzyl and (ii) a mixture of monomer (III) and monomer (II) with 4,4'-diaminodiphenyl methane by a low temperature solution polycondensation method. ${ }^{1}$
\end{abstract}<smiles>O=C(Cl)c1ccc(/C=N/c2ccc(Cc3ccc(/N=C/c4ccc(C(=O)Cl)cc4)cc3)cc2)cc1</smiles>

Monomer (III)

The copolyamides were characterized by solubility tests, viscosity measurements, UV, IR, emission spectroscopy, TGA, and DSC data. The spectral and thermal properties of the copolyamides are correlated to their structure and the effect of the new fluorescent diacid monomer unit and terephthaloyl unit on the thermal degradation of the copolymer was also studied.

KEY WORDS Fluorescence/ Polycondensation / Copolyamides / Extension of Conjugation / Azomethine Linkage / Terephthaloyl Group / Schiff's Base / Thermal Stability / Glass Transition Temperature /

Completely aromatic polyamides such as poly $(p$ phenylene terephthalamide) and polyamides synthesized from aromatic diamines and terephthaloyl chloride are well known for their chain stiffness and thermal stability. ${ }^{2,3}$ It was of considerable interest to investigate the thermal stability and other physical properties of these aromatic polyamides from terephthaloyl chloride by incorporating some new monomer units (comonomer) in the polymer backbone. The aromatic azomethine linkage is of special interest owing to the syn-anti isomerism exhibited by it and its effect on the thermal and photochromic properties ${ }^{4}$ of polymers warrants investigation. An aromatic azomethine group is fluorescent ${ }^{5}$ and it has been reported ${ }^{6}$ that the azomethine linkage $(-\mathrm{C}=\mathrm{N}-)$ in polyaromatic Schiff's bases provides greater stability toward thermal degradation compared to the amide $(-\mathrm{C}-\mathrm{N}-)$ group in polyamides. However no detailed investigation has been made on the effect of systematic modification of polyamides by the incorporation of the azomethine linking group in the aromatic polyamide backbone. In this paper, we report our results on the synthesis and characterization by solubility, viscosity, spectral (UV, IR, and emission spectroscopy), and thermal (TGA and DSC) studies of the new fluorescent aromatic copolyamides prepared by the condensation of diamines with a mixture of (i) monomer (I) and monomer (II) and (ii) monomer (III) and monomer (II) in a 1:1 ratio. The thermal stabilities of these polyamides is possibly associated with the effect of azomethine linking group on the polymer backbone.

\section{EXPERIMENTAL}

\section{Chemicals}

4,4'-Diaminodiphenyl ether (Fluka AG) was used without further purification. 4,4'-Diaminobibenzyl 
(Fluka AG) was recrystallized from dilute alcohol, and 4,4'-diaminodiphenylmethane (Koch-light) from dry benzene. The diacid chloride (I) was prepared as reported in our previous paper, ${ }^{7}$ by condensing terephthalaldehyde with 4-aminobenzoic acid and refluxing the pure diacid with excess of thionyl chloride in the presence of traces of pyridine as catalyst. Terephthaloyl chloride (II) was also prepared from terephthalic acid by the above method. The diacid chloride (III) was prepared by the above method using its diacid (monomer VI) obtained by the condensation of terephthalic acid and 4,4-diaminodiphenylmethane.

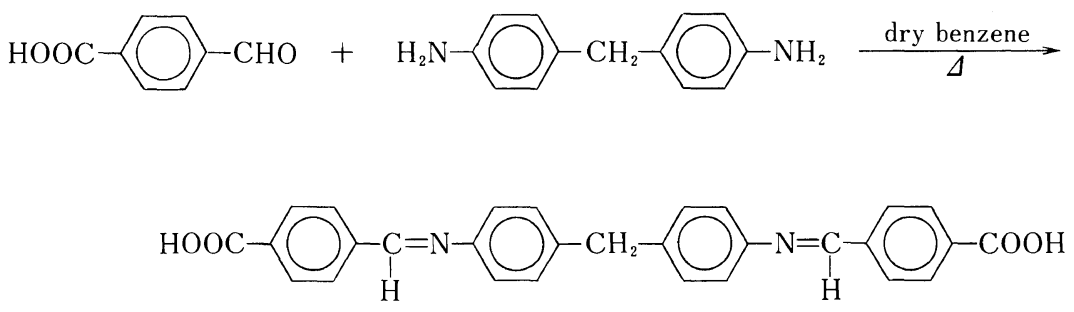

Monomer (VI)

The polymerization solvent $N, N$-dimethylacetamide (BDH, England) was treated with potassium hydroxide pellets and distilled over phosphorous pentoxide prior to use. Lithium chloride (SD's) was dried at $100^{\circ} \mathrm{C}$ in vacuum before use. Lithium carbonate (SD's) was used as it was.

\section{Polymerization}

All copolyamides were synthesized by the low temperature solution polycondensation method. In a typical experiment, the polymerization was carried out by adding a $1: 1$ mixture of diacid chlorides (I) and (II) to the chilled diamine solution in DMA/ $\mathrm{LiCl}$. The polymerization reached almost completion after $\sim 1 \mathrm{~h}$ at $-10^{\circ} \mathrm{C}$. The temperature was then raised to $25^{\circ} \mathrm{C}$ and the mixture stirred for one more hour to increase the viscosity. A sufficient amount of lithium carbonate was added to neutralize the liberated $\mathrm{HCl}$. Finally, the reaction mixture was filtered through a coarse glass frit and precipitated in cold water. Repeated water and acetone washes followed by vacuum drying of the filtered polymer at $80^{\circ} \mathrm{C}$ ensured a lithium free, monomer free, and moisture free copolyamide.

\section{Characterization of the Copolyamides}

Solubility. Solubility tests were carried out in DMA, DMSO, NMP, DMF, trifluoroacetic acid, and concentrated sulphuric acid. The effect of the addition of $\mathrm{LiCl}$ to DMA on the solubility of the copolyamides was also observed.
Viscosity. Viscosity measurements were carried out in an Ubbelohde suspended level viscometer at $25^{\circ} \mathrm{C}$ in concentrated sulphuric acid $\left(0.1 \mathrm{~g} \mathrm{dl}^{-1}\right)$.

Infrared spectra. The IR spectra of the copolyamides were taken in $\mathrm{KBr}$ pellets in a Beckman IR-20 spectrophotometer.

Ultraviolet Spectra. The UV spectra of the monomers and copolyamides were recorded with a Carl-Zeiss UV-VIS specord instrument in dry DMA.

Emission Spectra. The emission spectra of the monomers and copolyamides were recorded with an Aminco-Bowman spectrofluorometer in dry DMA in $10 \mathrm{~mm}$ cells.

Thermo-Gravimetric Analysis (TGA). The TGA data were obtained using a Du Pont 951 Thermal Gravimetric Analyser with a heating rate of $10^{\circ} \mathrm{C}$ $\min ^{-1}$ in nitrogen atmosphere.

Glass Transition Temperature $\left(T_{\mathrm{g}}\right)$. The glass transition temperature $T_{\mathrm{g}}$ was determined as the temperature corresponding to one-half the increase in heat capacity at the transition in DSC traces. ${ }^{8}$

Differential Scanning Calorimetry (DSC). The DSC data were obtained using a Du Pont 910 differential scanning calorimeter at a heating rate of $10^{\circ} \mathrm{C} \mathrm{min}^{-1}$ in nitrogen atmosphere.

\section{RESULTS AND DISCUSSION}

The polymerization procedure may be represented by the following reaction scheme. 
<smiles>Nc1ccc(Oc2ccc(N)cc2)cc1</smiles>

(I) $50 \%$

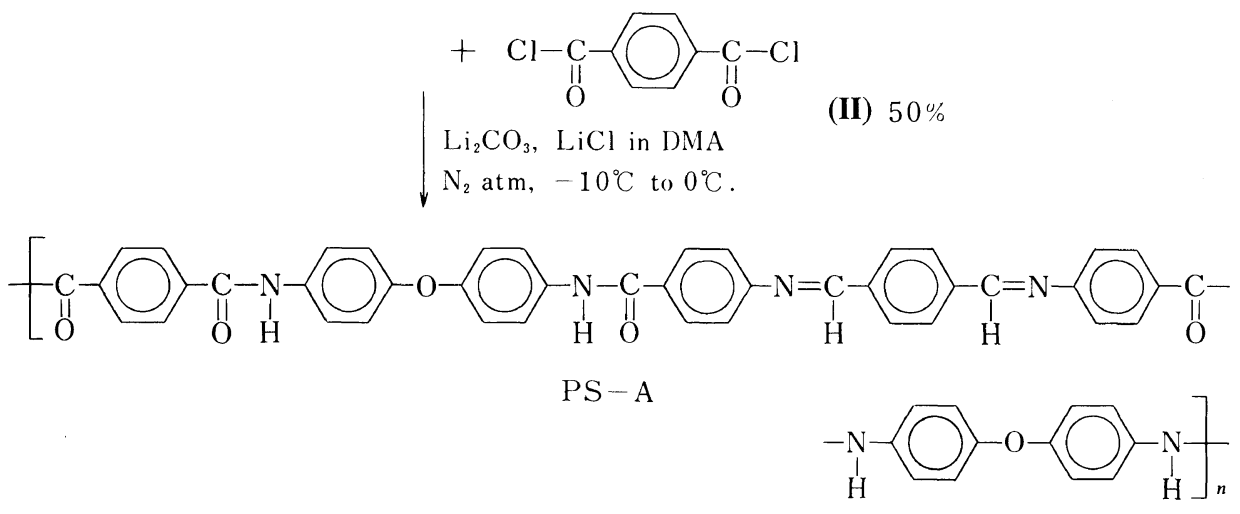

Table I. Synthesis conditions and inherent viscosities of the copolyamides

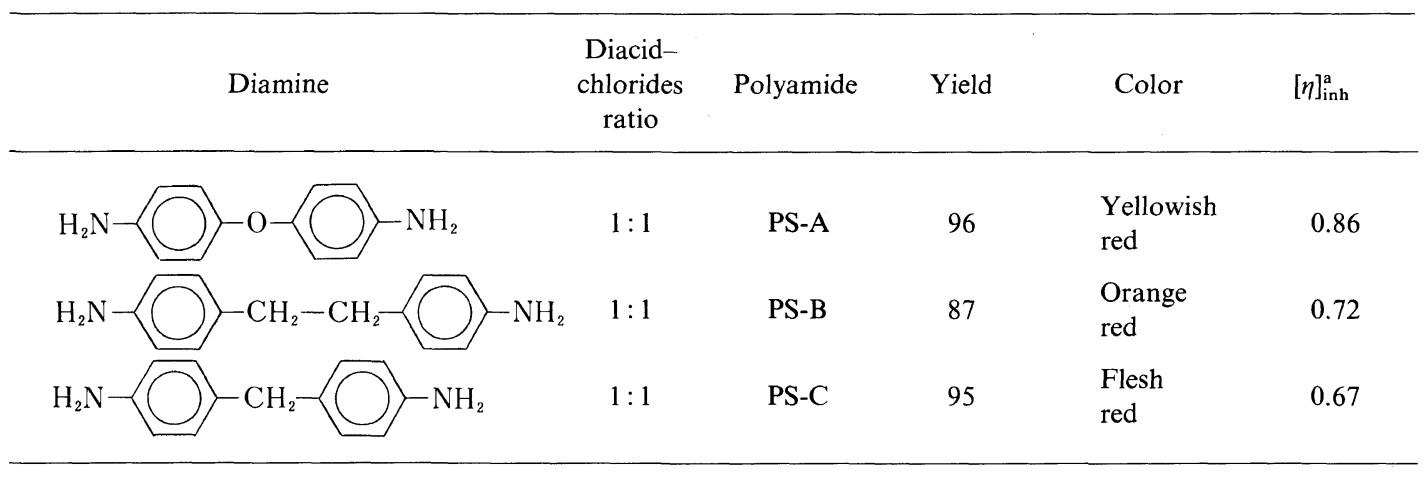

a $0.1 \mathrm{~g} \mathrm{dl}^{-1}$ of concd $\mathrm{H}_{2} \mathrm{SO}_{4}(98 \%)$ at $25^{\circ} \mathrm{C}$.

The color and inherent viscosities of the copolyamides are shown in Table I. From the viscosity data, it was observed that the molecular weight of the copolyamides was low. The high moisture sensitivity of the monomers (I) and (III) may be the cause for the lower molecular weight of the prepared polymers. The solubilities of the copolyamides are summarized in Table II. All three copolyamides were found to be easily soluble in concd $\mathrm{H}_{2} \mathrm{SO}_{4}$ and soluble in trifluoroacetic acid (TFA). The appreciable acid-base interaction between the above solvent molecules and the solute polymer molecules should be the cause for the high solubility. The copolyamides however were found to be insoluble in formic acid which is a good solvent only for aliphatic polyamides. The copolyamides were also found to be partially soluble in DMA and the
Table II. Copolyamide solubility

\begin{tabular}{lccc}
\hline \multirow{2}{*}{ Solvent $^{\mathrm{b}}$} & \multicolumn{3}{c}{ Solubility $^{\mathrm{a}}$} \\
\cline { 2 - 4 } & PS-1 & PS-2 & PS-3 \\
\hline Concd H$_{2} \mathrm{SO}_{4}$ & ++ & ++ & ++ \\
$\mathrm{CF}_{3} \mathrm{COOH}$ & + & + & + \\
$\mathrm{HCOOH}$ & - & - & - \\
DMA & \pm & \pm & \pm \\
DMA/LiCl & \pm & \pm & \pm \\
DMSO & - & - & - \\
DMF & - & - & - \\
NMP & - & - & - \\
\hline
\end{tabular}

a Solubility: $(++)$ easily soluble; $(+)$ soluble; $( \pm)$ partially soluble or swelling; ( - ) insoluble.

b DMA, dimethylacetamide; DMSO, dimethyl sulfoxide; DMF, dimethylformamide; NMR, $N$-methylpyrroliodone. 


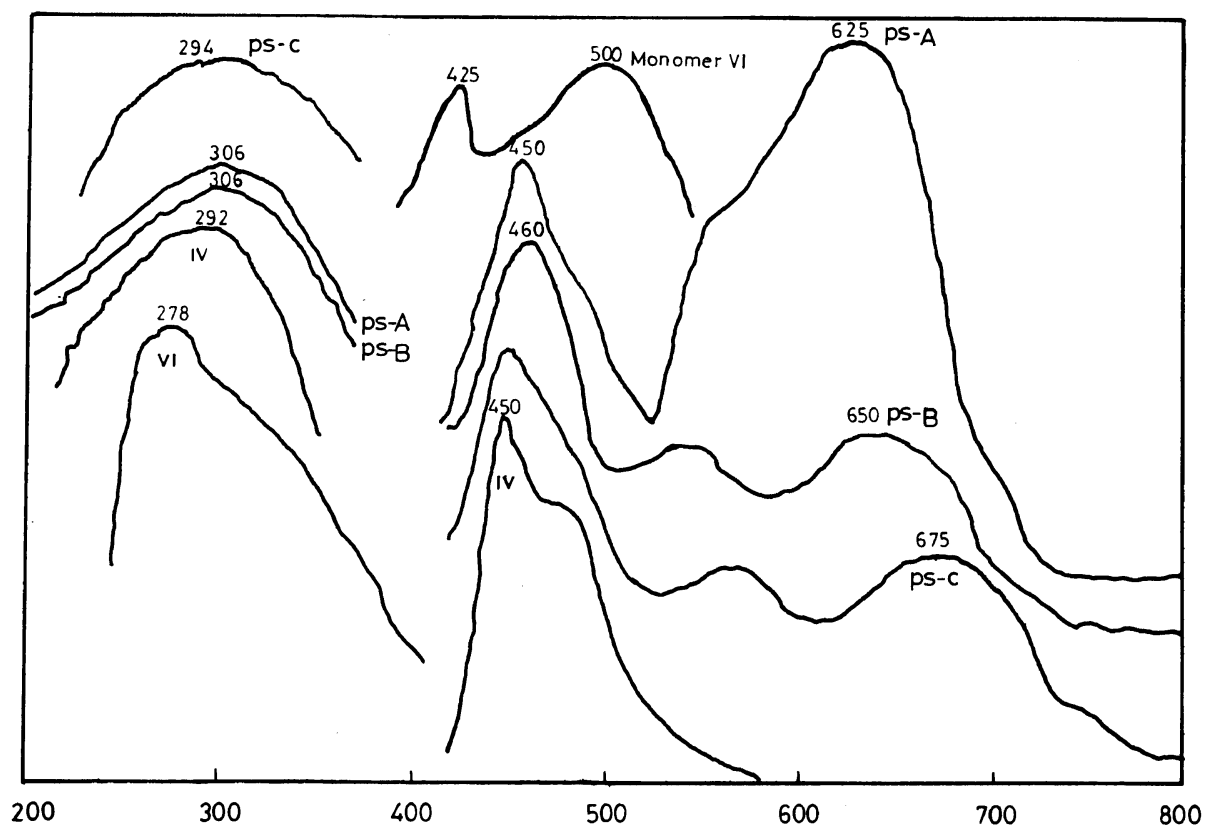

Figure 1. The absorption and emission spectra of monomer IV and monomer VI, copolyamides PS-A, PS-B, and PS-C.

addition of $\mathrm{LiCl}$ increased their solubility ${ }^{9}$ to a small extent. In all cases, it was difficult to redissolve the copolyamides in DMA or DMA/ $\mathrm{LiCl}$ after the copolymers were precipitated from the reaction solutions $(\mathrm{DMA} / \mathrm{LiCl})$ by suitable nonsolvents. The copolyamides were also found to be insoluble in DMSO, DMF, and NMP.

The absorption and emission maxima of the monomer 4,4'-[1,4-phenylene bis-(methylidyne nitrilo)]-di-(benzoic acid) (IV), monomer (VI), and the copolyamides prepared are shown in Figure 1. The monomer (IV) and (VI) showed absorption maxima at 292 and $278 \mathrm{~nm}$. Monomer IV showed an emission maximum at 450 while monomer VI, at 425 and $500 \mathrm{~nm}$. The NMR spectra of monomer VI were taken in trifluoroacetic acid using HMDS as the internal reference and are shown in Figure 4. Multiplets in the region 7.1 to $8.0 \delta$ are observed for the aromatic protons. A singlet at $9.0 \delta$ corresponding to the azomethine proton and another singlet at $3.7 \delta$ for benzyl protons are also observed $\left(\mathrm{Ph}-\mathrm{CH}_{2}-\right.$ $\mathrm{Ph})$. The copolyamides PS-A, PS-B, and PS-C showed absorption maxima at 306, 306, and $294 \mathrm{~nm}$ and emission maxima at 625,650 , and $675 \mathrm{~nm}$ respectively. The increase in both the absorption and emission maxima in going from the monomers to the polymers may be attributed to the extension of conjugation brought about by the amide group $^{10,11}$ formed during polymerization.

The IR spectra of the copolyamides are shown in Figure 2. In all the copolyamides, the stretching frequency of the carboxyl carbonyl group (1680$1690 \mathrm{~cm}^{-1}$ ) of the monomer (IV), monomer (VI) and terephthalic acid was absent and instead, the IR band corresponding to amide carbonyl (1645-1650 $\mathrm{cm}^{-1}$ ) appeared. The disappearance of the two bands corresponding to the primary amino group at $3400-3500 \mathrm{~cm}^{-1}$ followed by the appearance of a single band at $3290-3300 \mathrm{~cm}^{-1}$ on polymerization was also confirmed. From the IR data, the formation of amide linkages during polymerization could be deduced. The $-\mathrm{C}=\mathrm{N}$-stretching frequency was found to occur in the range $1600-1605 \mathrm{~cm}^{-1}$ in all three copolyamides. The experimentally determined percentage values of carbon, hydrogen, and nitrogen present in the monomers IV, and VI and polymers PS-A, PS-B, and PS-C were found to agree with the calculated values (Table IV). From the above spectral and elemental analyses data, the structures of the copolyamides have been confirmed as follows: 


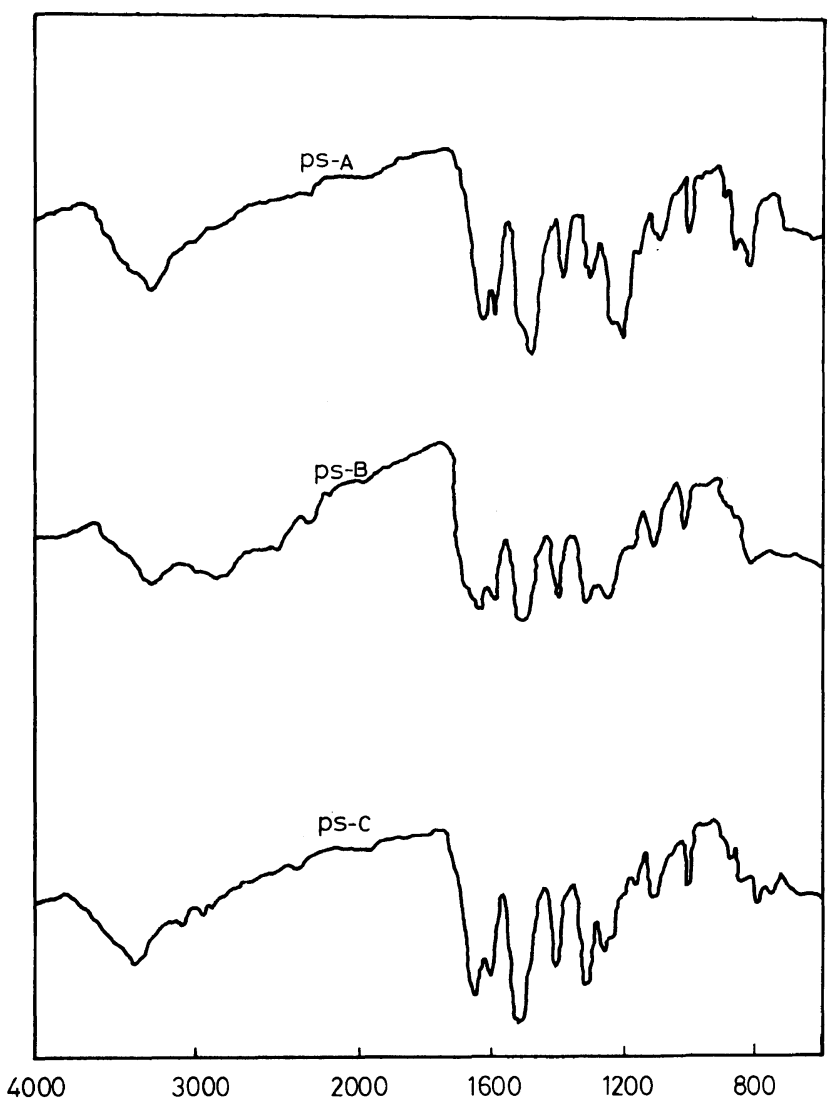

Figure 2. IR spectra of the copolyamides PS-A, PS-B, and PS-C.

PS-B<smiles>[2H]N(c1ccc(CCc2ccc(NC(=O)c3ccc(C(=O)C(C)(C)C)cc3)cc2)cc1)C(O)c1ccc(N=Cc2ccc(C=Nc3ccc(C(C)=O)cc3)cc2)cc1</smiles>

PS $-\mathrm{C}$<smiles>CNc1ccc(CCc2ccc(N3[CH]C4(C)CC34)cc2)cc1</smiles><smiles>CC=Nc1ccc(Cc2ccc(N=Cc3ccc(C(=O)Nc4ccc(Cc5ccc(NC(=O)c6ccc(C(=O)O)cc6)cc5)cc4)cc3)cc2)cc1</smiles>

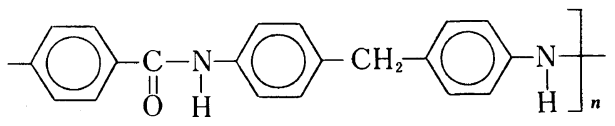




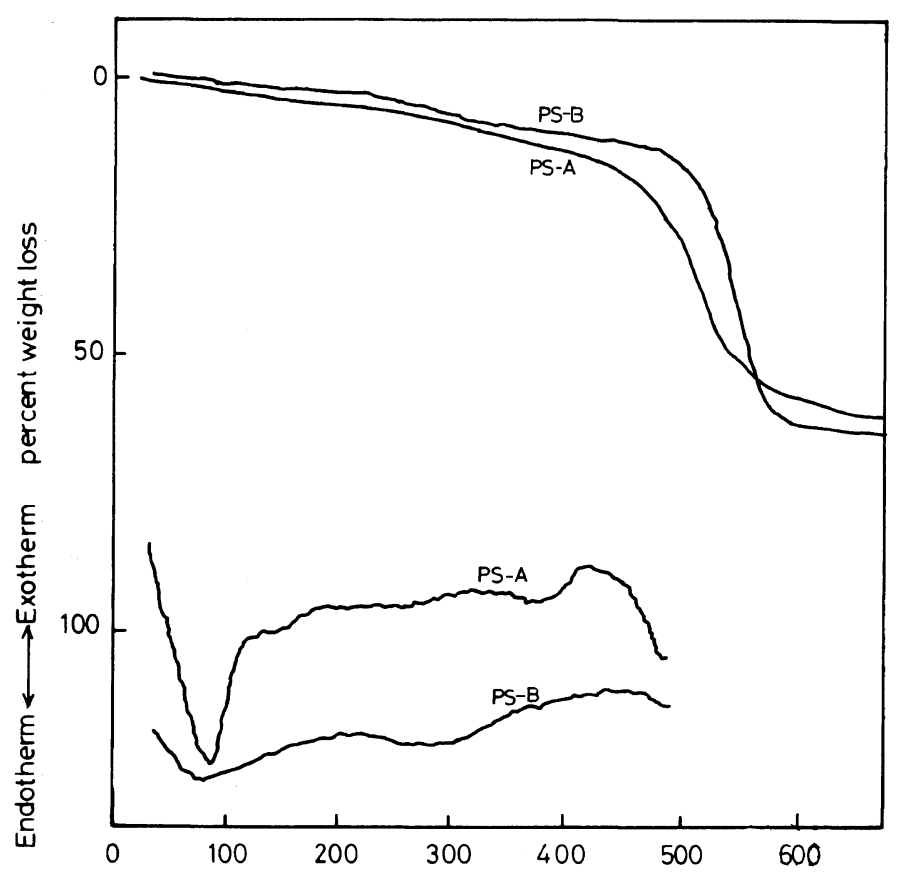

Figure 3. TGA and DSC curves of copolyamides PS-A and PS-B.

Table III. Copolyamides thermal data

\begin{tabular}{|c|c|c|c|c|c|}
\hline \multicolumn{4}{|c|}{$\mathrm{DSC}$} & \multicolumn{2}{|c|}{ TGA } \\
\hline \multirow{3}{*}{ Copolyamides } & \multirow{3}{*}{$\frac{\text { Endotherm }}{{ }^{\circ} \mathrm{C}}$} & \multirow{3}{*}{$\frac{\text { Exotherm }}{{ }^{\circ} \mathrm{C}}$} & \multirow{3}{*}{$\begin{array}{c}\text { Glass } \\
\text { transition } \\
\text { temp, } T_{\mathrm{g}} \\
{ }^{\circ} \mathrm{C}\end{array}$} & \multicolumn{2}{|c|}{ Thermal stability } \\
\hline & & & & $\begin{array}{l}\text { Temperature of } \\
10 \% \text { weight loss }\end{array}$ & $\begin{array}{l}\text { Temperature of } \\
50 \% \text { weight loss }\end{array}$ \\
\hline & & & & ${ }^{\circ} \mathrm{C}$ & ${ }^{\circ} \mathrm{C}$ \\
\hline PS-A & 87 (sharp) & 420 (broad) & 145 & 325 & 540 \\
\hline PS-B & $\begin{array}{l}80 \text { (broad) } \\
255\end{array}$ & 450 (broad) & 180 & 350 & 550 \\
\hline PS- $3^{a}$ & $\begin{array}{l}80,240 \text { (sharp) } \\
155 \text { (broad) }\end{array}$ & $\begin{array}{l}415 \text { (broad) } \\
445 \text { (starts) }\end{array}$ & 160 & 268 & 575 \\
\hline PS- $4^{\text {a }}$ & $80-130$ (broad) & $\begin{array}{l}315 \text { (sharp) } \\
400 \text { (starts) }\end{array}$ & 235 & 200 & 675 \\
\hline
\end{tabular}

${ }^{a}$ PS-3 and PS-4 are simple polyamides synthesized by condensing monomer I with 4,4'-diaminobibenzyl and 4,4'diaminodiphenyl ether.

\section{Thermal Properties}

The TGA and DSC curves of PS-A and PS-B are shown in Figure 3. The thermal analysis data are given in Table III. From the TGA curves of PS-A and the polyamide PS- $4^{12}$ it was found that the introduction of terephthaloyl group, by as much as $50 \%$ in the polymer backbone, changed the thermal behavior of the copolyamide PS-A considerably. In the case of polyamide PS-4, a $50 \%$ weight loss occurred at $675^{\circ} \mathrm{C}$ whereas the copolyamide PS-A 


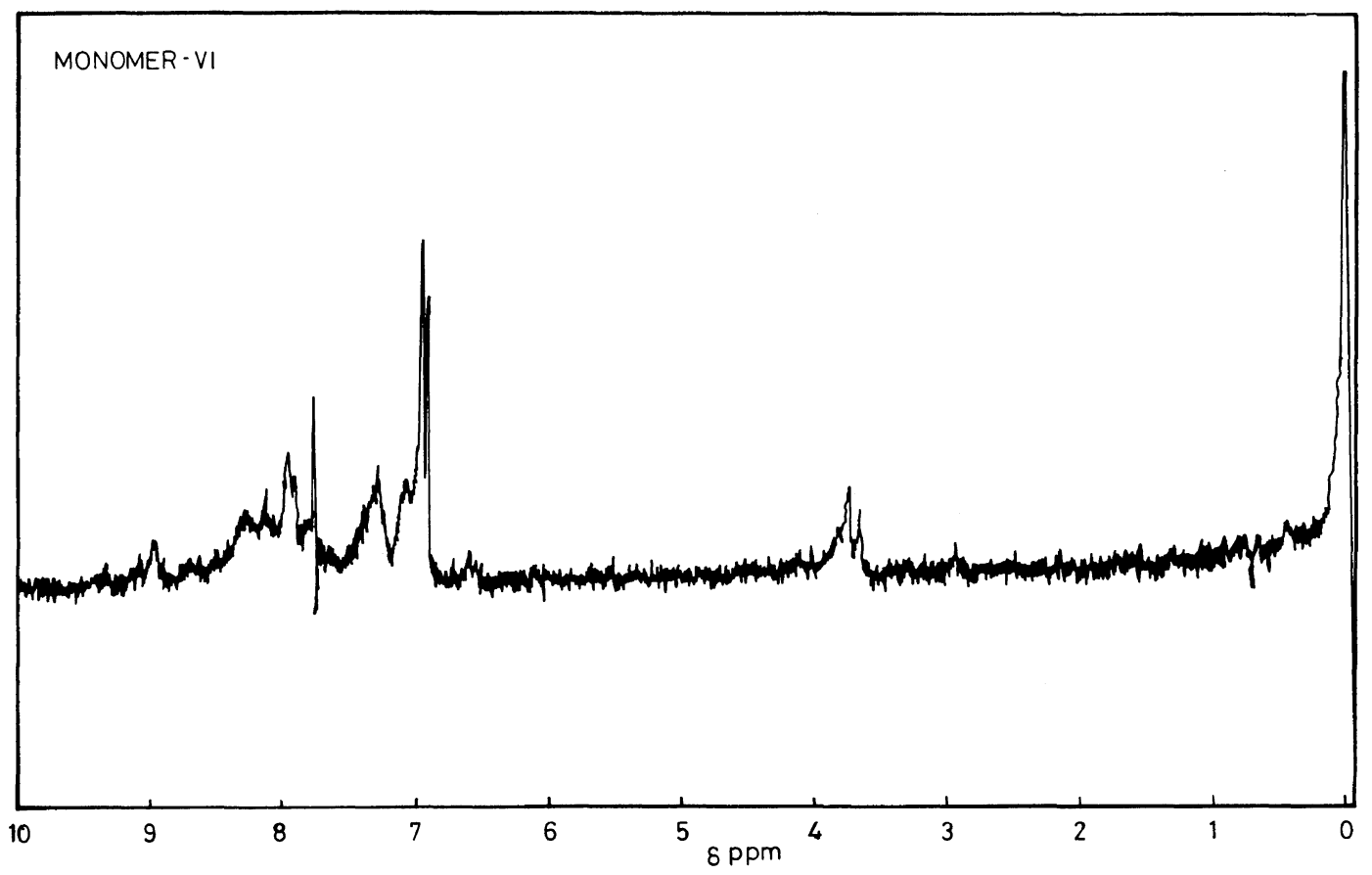

Figure 4. NMR spectrum of monomer VI.

Table IV. Elemental analysis data of monomers and polymers

\begin{tabular}{|c|c|c|c|c|c|c|}
\hline \multirow{3}{*}{ Monomer/Polymer } & \multicolumn{6}{|c|}{ Elemental analysis } \\
\hline & \multicolumn{2}{|c|}{$\mathrm{C} \%$} & \multicolumn{2}{|c|}{$\mathrm{H}^{\circ} \%$} & \multicolumn{2}{|c|}{$\mathrm{N} \%$} \\
\hline & (Found) & (Calcd) & (Found) & (Calcd) & (Found) & (Calcd) \\
\hline Monomer IV $\left(\mathrm{mp}>300^{\circ} \mathrm{C}\right)$ & 70.71 & 70.96 & 4.47 & 4.33 & 7.23 & 7.52 \\
\hline Monomer VI $\left(\mathrm{mp}>300^{\circ} \mathrm{C}\right)$ & 75.05 & 75.31 & 4.96 & 4.79 & 5.87 & 6.06 \\
\hline PS-A & 74.59 & 74.81 & 4.70 & 4.42 & 9.51 & 9.70 \\
\hline PS-B & 77.92 & 78.18 & 5.31 & 5.20 & 9.22 & 9.43 \\
\hline PS-C & 79.17 & 79.39 & 5.29 & 5.08 & 8.58 & 8.82 \\
\hline
\end{tabular}

showed a $50 \%$ weight loss at $540{ }^{\circ} \mathrm{C}$. From this, it is evident that the introduction of a terephthaloyl group decreases the thermal stability of the copolyamide considerably. A similar effect was also observed in the case of PS-B. Though the glass transition temperature of copolyamide PS-A is lower $\left(145^{\circ} \mathrm{C}\right)$ compared to that of the polyamide PS-4 $\left(235^{\circ} \mathrm{C}\right),{ }^{12}$ the difference in the $T_{\mathrm{g}} \mathrm{s}$ of copolyamide PS-B $\left(180^{\circ}\right)$, and polyamide $\mathrm{PS}-3\left(160^{\circ} \mathrm{C}\right)^{12}$ is quite small. Thus, the incorporation of a terephthaloyl unit in the backbone of a polyamide changes the glass transition temperature also.

The change in $T_{\mathrm{g}}$ value of the copolyamide PS-A from that of the simple polyamide PS-4 may be attributed to a configuration which effects the close packing of the polyamide and copolyamide chains. In the case of PS-4, the presence of an ether linkage $(, \mathrm{O})$ in the diamine part influences the polymer chain to assume preferentially a helical structure. Now, the close packing of the helical polymer chains may lead to high crystallinity, thereby increasing the $T_{\mathrm{g}}$ value $\left(235^{\circ} \mathrm{C}\right)$. As the linear tere- 
phthaloyl group is introduced into the backbone of PS-4, the helical structure is disturbed in the resulting copolyamide PS-A, thus decreasing the crystallinity and hence the $T_{\mathrm{g}}$ value. $\left(145^{\circ} \mathrm{C}\right)$.

In the case of PS- $3,{ }^{12}$ the $-\mathrm{CH}=\mathrm{N}$-linkage in the diacid part may have a syn-anti configuration. In order to achieve maximum crystallinity through close packing, this linkage should have anti configuration which may not be realized in polymer PS3 thus leading to a lower $T_{\mathrm{g}}$ value $\left(160^{\circ} \mathrm{C}\right)$. The introduction of the linear terephthaloyl unit introduces more linearity in the copolyamide (PS-B) chains thus leading to an increase in crystallinity. Therefore the $T_{\mathrm{g}}$ value of the copolyamide PS-B is slightly higher $\left(180^{\circ} \mathrm{C}\right)$ than that of PS-3.

Acknowledgements. We wish to express our deep gratitude to Professor N. Grassie, University of Glasgow for his very kind assistance in obtaining the thermal analysis data for our polymer samples. Financial support was received by one of us (P.S) from the U.G.C. in the form of SRF and is gratefully acknowledged.

\section{REFERENCES}

1. P. W. Morgen, "Condensation Polymers by Interfacial and Solution Method," Interscience Publishers, New York, 1965, p 483.

2. H. G. Mark, S. M. Atlas, and N. Ogata, J. Polym. Sci., 61, 549 (1962).

3. R. A. Dine-Hart, B. J. C. Moore, and W. W. Wright, J. Polym. Sci., B, 2, 363 (1964).

4. R. S. Becker and W. F. Richey, J. Am. Chem. Soc., 89, 1298 (1967).

5. A. P. Terent'ev, E. G. Rukhadze, G. P. Talyzenkova, and C. V. Panova, Zh. Obstich. Khim., 36(9), 1590 (1966).

6. A. D. Delman, A. A. Stein, and B. B. Simms, "High Temperature Polymers," C. L. Segal, Ed., Marcel Dekker Inc., New York, 1967, p 147.

7. P. Subramanian and K. Venkatarao, Makromol. Chem. Rapid, Commun., 2, 179 (1981).

8. M. Jayabalan, J. Appl. Polym. Sci., 27, 43 (1982).

9. M. Panar and L. F. Baste, Macromolecules, 10, 1401 (1977).

10. J. Eric Riodran and Hal S. Blair, Polymer, 20, 196 (1979).

11. W. West, Ed., in "Chemical Applications of Spectroscopy (Technique of Organic Chemistry, Vol. 9)," Interscience, New York, 1956, Chapter 6.

12. P. Subramanian and K. Venkatarao, Makromol. Chem., in press. 